\title{
Dose response of ipratropium bromide assessed by two methods
}

\author{
CHRISTOPHER J ALLEN AND ALASTAIR H CAMPBELL
}

From the Division of Thoracic Medicine, Repatriation General Hospital, Heidelberg, Australia

ABSTRACT The dose-response relationships of ipratropium bromide were assessed by two different techniques in two groups of 10 male patients with partially reversible airways obstruction. In a randomised double-blind fashion on four days, 10 patients were given $40 \mu \mathrm{g}, 80 \mu \mathrm{g}$, or $120 \mu \mathrm{g}$ of ipratropium bromide or placebo from identical containers. Baseline $\mathrm{FEV}_{1}$ and vital capacity were measured and the measurements repeated after 40 minutes, one, two, four, and six hours, and any symptoms were elicited. In the second study, each patient received cumulative doses of $40 \mu \mathrm{g}, 80 \mu \mathrm{g}$, and $120 \mu \mathrm{g}$. Baseline $\mathrm{FEV}_{1}$ was obtained and repeated 35 minutes after each dose. The peak increase of the $\mathrm{FEV}_{1}$ was comparable in both studies. The $\mathrm{FEV}_{1}$ was slightly greater after $120 \mu \mathrm{g}$ than after $40 \mu \mathrm{g}$. Although this reached statistical significance only in the first study, it was concluded that the cumulative dose-response technique was suitable for determining the peak response. However, this technique was unsuitable for assessing duration of effect, which could be examined only in the first study. After $120 \mu \mathrm{g}$ of ipratropium bromide, the $\mathrm{FEV}_{1}$ was significantly greater than after $40 \mu \mathrm{g}$ at each time interval and it was greater than $80 \mu \mathrm{g}$ at six hours $(\mathrm{p}<0.05)$. No significant side effects were noted in either study. When prolonged effective bronchodilation is sought, a dose of $120 \mu \mathrm{g}$ of ipratropium bromide may be preferable to the recommended dose of $40 \mu \mathrm{g}$.

The anticholinergic bronchodilator ipratropium bromide is a quarternary ammonium derivative of atropine. Its quarternary structure prevents it crossing the blood-brain barrier and causing central effects. As an aerosol it is highly specific and virtually free of side effects even in doses well in excess of those recommended. ${ }^{12}$

It has been reported that the recommended dose, $40 \mu \mathrm{g}$ from a metered dose inhaler, achieves a peak bronchodilator effect. ${ }^{3}$ Nevertheless, higher doses may prolong the duration of bronchodilatation $^{4}$.

To assess both the peak bronchodilation and the duration of the response, we have determined the dose-response relationships of ipratropium bromide with two different techniques. In the first study we administered the test doses on different days. In this way we were able to assess the peak response, duration of action, and unwanted side effects. The second study employed a cumulative dose-response technique. ${ }^{6}$ It is simpler and allows several doses of a drug to be assessed over a short

Address for reprint requests. Dr AH Campbell, Repatriation General Hospital, Heidelberg 3077, Australia. period of time, and the peak effect and unwanted effects can be determined. Its limitation is that it does not allow the duration of action to be assessed.

\section{Methods}

A group of 16 male patients gave informed consent to taking part in the investigation. All had asthma characterised by episodes of wheeze and shortness of breath requiring bronchodilators for relief of symptoms, and 12 were receiving beclamethasone dipropionate by inhalation or oral corticosteroids or both. Only six of the 16 patients had positive skin tests to common allergens and all but one had chronic productive cough. Eleven were current cigarette smokers.

\section{SINGLE DOSE STUDIES}

For the first study, 10 male patients were admitted to hospital in a stable condition. Bronchodilators were withheld for at least nine hours before any test. However, steroids were continued unchanged.

In a randomised, double-blind fashion on four 
days (consecutive where possible), the 10 patients studied were given $40 \mu \mathrm{g}, 80 \mu \mathrm{g}$, or $120 \mu \mathrm{g}$ of aerosol ipratropium bromide or placebo from identical containers. Two unlabelled containers were used, containing either placebo or active agent $(20 \mu \mathrm{g}$ per puff), so that the patient each day received six puffs of aerosol over 90 seconds.

Each study started at about $0900 \mathrm{hr}$. Baseline measurements of forced expiratory volume in one second $\left(\mathrm{FEV}_{1}\right)$ and vital capacity (VC) were performed, and the best of three readings taken. The patient then inhaled the aerosol. At $\mathbf{4 0}$ minutes, one, two, four, and six hours after the aerosol measurements of $\mathrm{FEV}_{1}$ and VC were performed. Again the best of three measurements was taken, corrected to BTPS. Symptoms were recorded before each measurement. Baseline measurements each day were within $15 \%$ of each other. Tests were postponed when the baseline values were outside this range. The significance of the results obtained was analysed using analysis of variance.

\section{CUMULATIVE DOSE-RESPONSE STUDY}

For the cumulative dose-response study, 10 male outpatients were assessed (four common to the first study). Bronchodilators were withheld as before.

The peak effect of ipratropium bromide is not reached until about $30-40$ minutes. $^{3}$ This peak is then maintained for two to three hours. For this reason, after baseline measurements of $\mathrm{FEV}_{1}$ and $\mathrm{VC}$, and then the inhalation of $40 \mu \mathrm{g}$ of ipratropium bromide, 35 minutes were allowed to elapse before three measurements of $\mathrm{FEV}_{1}$ were made. The patient then inhaled another $40 \mu \mathrm{g}$ and the measurements were repeated beginning 35 minutes after this dose. A third dose of $40 \mu \mathrm{g}$ was then inhaled and measurements repeated $35 \mathrm{~min}$ utes later.

In this way, the patient received cumulative doses of $40 \mu \mathrm{g}, 80 \mu \mathrm{g}$, and $120 \mu \mathrm{g}$. The best of three $\mathrm{FEV}_{1}$ readings were taken each time. The readings were uncorrected because of the brief duration of the investigation. Symptoms were elicited after each dose. The significance of the results were analysed using analysis of variance.

\section{Results}

SINGLE DOSE STUDIES

The baseline mean $\mathrm{FEV}_{1}$ values before placebo and to each dose of ipratropium bromide did not differ significantly. The mean and range in litres before placebo, $40 \mu \mathrm{g}, 80 \mu \mathrm{g}$, and $120 \mu \mathrm{g}$ of ipratropium bromide were $1.08(0.40-1.80), 1.06(0.40$ $1.70), 1.09(0.40-1.90)$.
Compared with the placebo, each dose of ipra tropium bromide produced a significant increase of the mean $\mathrm{FEV}_{1}(\mathrm{p}<0.05)$. This was found up tof two hours for the $40 \mu \mathrm{g}$ dose and up to six hour 8 with the $80 \mu \mathrm{g}$ and $120 \mu \mathrm{g}$ doses. Given the basew line value, after $80 \mu \mathrm{g}$ the $\mathrm{FEV}_{1}$ was significantly greater than after $40 \mu \mathrm{g}$ at four hours $(\mathrm{p}<0.05)_{2}^{\circ}$ whereas for $120 \mu \mathrm{g}$ the $\mathrm{FEV}_{1}$ was significantl. greater than $40 \mu \mathrm{g}$ at all times except zero and was greater than $80 \mu \mathrm{g}$ at six hours $(\mathrm{p}<0.05)$ (fig 1$) \overrightarrow{{ }_{2}}$ Apart from a dry cough in one patient after $120 \mu$ there were no side effects.

\section{CUMULATIVE DOSE-RESPONSE STUDY}

The results for the cumulative dose response studif are shown in fig 2. The mean baseline $\mathrm{FEV}_{1}$ was 1.061 (range $0.38-2.031$ ). After $40 \mu \mathrm{g}$ there waळ a significant increase in mean $\mathrm{FEV}_{1}$ of 0.30 里

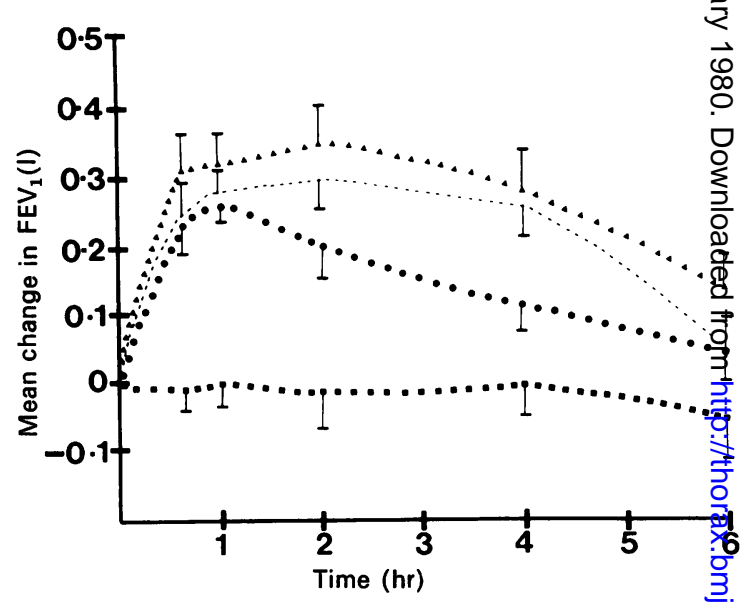

Fig 1 Mean incrca $e \pm S E M$ of FEV ${ }_{1}$ after different $\delta$ doses of ipra:rop:um bromide, $n=10$. $\Delta=120 \mathrm{mcg}$, ... = $80 \mathrm{mcg}, \ldots 40 \mathrm{mcg} \square \square$ placebo.

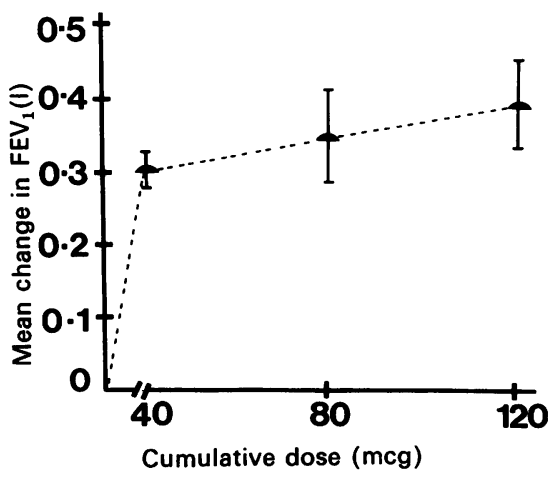

Fig 2 Mean increase $\pm S E M$ of FEV after cumulative doses of ipratropium bromide. $n=10$. 
$(28 \%)$ compared to the mean baseline $\mathrm{FEV}_{1}$. After a cumulative dose of $80 \mu \mathrm{g}$ there was a further rise of $6 \%$, and after a cumulative dose of $120 \mu \mathrm{g}$, a further rise of $3 \%$ in $\mathrm{FEV}_{1}$, though neither of these latter changes was statistically significant.

No side effects were recorded.

\section{Discussion}

Using two different methods we found a small increase in the peak bronchodilatation when doses of $80 \mu \mathrm{g}$ and $120 \mu \mathrm{g}$ of ipratropium bromide were compared with $40 \mu \mathrm{g}$. The differences were not statistically significantly in the cumulative dose study, but reached significance at the 5\% level with the dose of $40 \mu \mathrm{g}$ versus $120 \mu \mathrm{g}$ administered on separate days. Ruffin and Newhouse ${ }^{5}$ found that $60 \mu \mathrm{g}$ of ipratropium bromide gave a significantly greater peak maximum mid-expiratory flow rate than $20 \mu \mathrm{g}$ and $40 \mu \mathrm{g}$, but no difference for peak FEV $_{1}$. Most other studies, ${ }^{4}{ }^{7}$ have failed to show that doses of ipratropium bromide above $40 \mu \mathrm{g}$ produce a greater response than that achieved by $40 \mu \mathrm{g}$. The improvement in the peak response in the present study was small. It can be concluded that a dose of $40 \mu \mathrm{g}$ of ipratropium bromide produces close to the peak response obtainable. The investigation has shown that the cumulative dose-response technique is suitable for determining the peak response. However, the technique does not allow assessment of duration of effect. For this, the more troublesome procedure of administering doses on different days is necessary. Ruffin and Newhouse ${ }^{5}$ have shown previously that $60 \mu \mathrm{g}$ of ipratropium bromide gives a significantly longer duration of action than $20 \mu \mathrm{g}$ or $40 \mu \mathrm{g}$, whereas Baigelman and Chodosh ${ }^{4}$ found in a group of chronic bronchitics that $80 \mu \mathrm{g}$ gave a significantly longer lasting effect than $40 \mu \mathrm{g}$. In the present investigation it was found that $120 \mu \mathrm{g}$ produced significant bronchodilatation for at least six hours. It was superior to $40 \mu \mathrm{g}$ and marginally better than $80 \mu \mathrm{g}$. The patients investigated may have been particularly responsive to anticholinergic drugs. They all had asthma but were investigated when relatively stable and most were receiving steroids. All but one had chronic productive cough consistent with chronic bronchitis.
Only six had positive skin reactions to ccmmon allergens. Patients with these characteristics may be more responsive to anticholinergic drugs than other asthmatics. ${ }^{8} 9$

For the type of patient studied, our results show that $120 \mu \mathrm{g}$ of ipratropium bromide offers a higher peak and longer duration of bronchodilatation than the usually recommended dose of $40 \mu \mathrm{g}$. The dose of $120 \mu \mathrm{g}$ was well tolerated, and provided this is confirmed, this dose of ipratropium bromide may prove useful to obtain prolonged effective bronchodilation in clinical practice.

\section{References}

1 Wood MJ, Paterson JW. Evaluation of cumulative doses of Sch 1000 in asthmatics. Postgrad Med J 1975; 51, Supplement 7:100.

2 Simonsson BG, Jonson B, Ström B. Bronchodilatory and circulatory effects of inhaling increasing doses of an anti-cholinergic drug, ipratropium bromide (Sch 1000). Scand J Respir Dis 1975; 56:138-149.

3 Loddenkemper $R$. Dose and time response of Sch 1000 MDI on total (Rt) and expiratory ( $R e)$ airways resistance in patients with chronic bronchitis and emphysema. Postgrad Med J 1975; 51, Supplement 7:97.

4 Baigelman W, Chodosh S. Bronchodilator action of the anticholinergic drug ipratropium bromide (Sch 1000) as an aerosol in chronic bronchitis and asthma. Chest 1977; 71:324-328.

5 Ruffin RE, Newhouse MT. Ipratropium bromide (Sch 1000) monohydrate aerosol: bronchodilator effect of three dose levels in asthmatics. Lung 1978; 155:141-46.

6 Shenfield GM, Paterson JW. Clinical assessment of bronchodilator drugs delivered by aerosol. Thorax 1973; 28:124-8.

7 Gross HJ. Dose response study of the effect of Sch $1000 \mathrm{MDI}$ as forced vital capacity (FVC), $\mathrm{FEV}_{1.0}$, maximal mid-expiratory flow (MMEF) and heart rate, E.C.G. and blood pressure. Postgrad Med J 1975; 51, Supplement 7:95.

8 Altounyan REC. Variation of drug action on airway obstruction in man. Thorax 1964; 19:406-15.

9 Ruffin RE, Fitzgerald JD, Rebuck AS. A comparison of the bronchodilator activity of Sch 1000 and salbutamol. J Allergy Clin Immunol 1977; 59:136-41. 